\title{
Should nutritional status evaluation be included in the initial needs assessment of leprosy patients with disability prior to socio-economic
}

\author{
MARIO VAZ*, BRONWYN DIFFEY**, \\ AUBURN J. W. JACOB+ \& MANJULIKA VAZ++ \\ *Division of Nutrition, Department of Physiology, St John's Medical \\ College, Bangalore 560034, India \\ **School of Health Sciences, Deakin University, Burwood, Victoria, \\ Australia \\ +Emmaus-Swiss Leprosy Project, PO Palamaner 517408, Andhra \\ Pradesh, India \\ ++The P \& P Group, Wilson Gardens, Bangalore 560027, India
}

Accepted for publication 4 April 2001

\begin{abstract}
Summary Because of the large numbers of leprosy patients with disability and the limited resources available, it is important that socio-economic rehabilitation (SER) is targeted towards those who are most in need. Towards this purpose, current assessments of leprosy patients prior to initiating SER include the evaluation of income, assets and household possessions. Conspicuously absent is the nutritional assessment of the patient. In the absence of weight loss associated with illness, population studies indicate that undernutrition reflects poor socio-economic conditions. In this study of 151 cured leprosy patients with disability, $57 \%$ of the patients were found to be undernourished using body mass index $\left(\mathrm{kg} / \mathrm{m}^{2}\right)$ derived from body weight and height, and $10 \%$ of the patients were severely undernourished (grade III). Undernutrition in the patients was poorly though significantly correlated with personal income $(r=0.18$, $P<0.05)$. Total household income, reported amount of money spent on food and estimated cereal intakes were not correlated with the BMI of the patient, possibly due to reporting bias and other methodological issues. We propose the inclusion of nutritional status evaluation by anthropometry as part of the initial screening of leprosy patients prior to instituting SER. We believe that this simple and objective evaluation can add to the assessment of 'threat' of economic deprivation or actual economic 'dislocation', and thus help in the prioritization of leprosy patients for SER.
\end{abstract}

\section{Introduction}

While considerable efforts have been made to reduce the development of disability in leprosy patients, there are still a large number of cured leprosy patients with residual deformity. ${ }^{1}$ In 
India, for instance, it is estimated that there are 1 million individuals with disabilities attributable to past and present leprosy. ${ }^{1}$ The leprosy patient with deformity has unique sociocultural problems. These include, among others, a lower acceptance in the community ${ }^{2,3}$ and lower incomes. ${ }^{3,4}$

One of the tasks undertaken by personnel working with leprosy patients is the socioeconomic rehabilitation (SER) of leprosy patients with disability. This has, in fact, been listed as a priority area for leprosy programme planners. ${ }^{5}$ In a situation where economic resources are limited, and the numbers of people with disability are large, ${ }^{6}$ the process of rehabilitation needs to be targeted to those most in need. In this context, it has been suggested that in assessing rehabilitation needs, simple counts of those with impairments will not suffice. ${ }^{7}$ Indeed, people with impairments (even deformity) are not necessarily in need of rehabilitation. ${ }^{5}$ It has now been suggested that (i) individuals with physical disability whose social and economic life is under threat, or (ii) already economically dislocated patients, should be the primary targets of SER ${ }^{8}$ Gopal, based on a large survey in India, estimated these numbers to be 2.5 and $9 \%$ of the total leprosy population, respectively. ${ }^{9}$ The challenge in the first instance, clearly, is to identify these individuals. In order to do this, it is recommended that initial screening of disabled individuals should include an assessment of financial status, including employment history, earnings, assets and liabilities before the disease as well as an assessment of employment and economic impact of leprosy. ${ }^{8}$ Some of these indicators, however, are subjective and can possibly have a reporting bias. It is our contention that the objective evaluation of nutritional status in disabled leprosy patients can help separate out those who are economically deprived from those who are not, and can add valuable information to the initial needs assessment aimed at identifying individuals most in need of SER.

This paper explores, in part, the theoretical construct outlined in Figure 1 which illustrates the possible links of nutritional status with other economic indices, some of which are used in the initial needs assessment of leprosy patients with disability. In so doing, we propose that nutritional status evaluation using simple anthropometric measures be included as part of the needs assessment of leprosy patients with disability.

\section{Materials and methods}

This analysis is based on 151 cured, adult leprosy patients with residual disability. This data set is a sub-sample of a larger study reported earlier, ${ }^{3}$ and includes all the leprosy patients with disability of that study. Fifty-two of the leprosy patients were women. This sample of cured leprosy patients comprised $12 \%$ of the total number of living leprosy patients with deformity registered at the Emmaus Swiss Leprosy Project in Palamaner, South India, the site where the study was conducted.

The details of the sampling strategy have been described earlier. ${ }^{3}$ Briefly, patients were motivated to attend the mobile leprosy clinic services, during which a nutritional assessment was performed by a trained nutritionist accompanying the clinic team. The nutritional assessment included basic anthropometry at the clinic site. In addition, paramedical workers also filled in a questionnaire during home visits prior to the clinic. This questionnaire related to the detailed evaluation of deformity status and the purchase of food staples. The extent of disability was assessed using the method of Bechelli and Dominguez. ${ }^{10}$ The cereal energy intake of the index case was assessed by applying appropriate consumption units to the 
household cereal supply. ${ }^{11}$ The anthropometric assessment included height and weight of all subjects. Nutritional status was determined using body mass index (BMI: weight in $\mathrm{kg} /$ height $^{2}$ in $\mathrm{m}$ ) cut-offs described earlier. ${ }^{12,13}$ Thus, well nourished subjects had BMIs of $>18.5$. Chronic undernutrition of varying grades was identified as follows: grade I = BMI 17-18.5, grade $\mathrm{II}=16$ to $<17$, grade III $=\mathrm{BMI}<16$.

All data are presented as mean \pm standard deviation (SD). In order to facilitate analysis, leprosy patients were divided into four groups (well nourished, and three grades of undernutrition). A comparison of parameters in these four groups was done using a one-way analysis of variance (ANOVA). The null hypothesis was rejected at $P<0.05$.

\section{Results}

Table 1 summarizes the characteristics of the cured leprosy patients with residual deformity classified into four nutritional groups. The age of the patient, the extent and duration of disability, and the prevalence of unemployment were similar in all nutritional groups. The total household income of leprosy patients with grade III undernutrition was $70 \%$ of that of well-nourished leprosy patients (not statistically significant), and was explained almost entirely by the loss of earnings in the index case. Despite the $\sim 30 \%$ lower total income in the households of patients with grade III undernutrition, the amount of money reportedly spent on food was comparable across all groups. The cereal-based daily energy intake of leprosy patients with grade III undernutrition was $>20 \%$ lower than patients who were well nourished, although this difference was not statistically significant.

When the data of all groups were pooled, the income of the leprosy patient was, significantly, albeit poorly correlated with the BMI of the leprosy patient ( $r=0.18, P=0.03$ ).

Table 1. Characteristics of index cases with deformity

\begin{tabular}{|c|c|c|c|c|c|}
\hline Parameter & Well nourished & $\begin{array}{l}\text { Undernourished } \\
\text { Grade } 1\end{array}$ & Grade II & Grade III & $P$-value \\
\hline Number & 65 & 47 & 23 & 15 & \\
\hline $\mathrm{BMI}\left(\mathrm{kg} / \mathrm{m}^{2}\right)$ & $20.8 \pm 0.4$ & $17.8 \pm 0.4$ & $16.6 \pm 0.3$ & $15.1 \pm 0.5$ & 0.000 \\
\hline $\begin{array}{l}\text { Age of index case } \\
\text { (years) }\end{array}$ & $41.4 \pm 7.9$ & $41.5 \pm 7.9$ & $42.4 \pm 6.2$ & $38.6 \pm 8.1$ & 0.503 \\
\hline Disability index & $1.92 \pm 1.18$ & $1.9 \pm 1.19$ & $1.96 \pm 1.0$ & $1.77 \pm 1.0$ & 0.962 \\
\hline $\begin{array}{l}\text { Duration of deformity } \\
\text { (years) }\end{array}$ & $10.3 \pm 6.6$ & $11.9 \pm 8.0$ & $10.1 \pm 7.1$ & $11.9 \pm 6.4$ & 0.548 \\
\hline Number unemployed & $21(32.3 \%)$ & $17(36.2 \%)$ & $12(52.1 \%)$ & $4(26.7 \%)$ & $\begin{array}{l}\text { Chi } \\
\text { square: } \\
\text { NS }\end{array}$ \\
\hline $\begin{array}{l}\text { Household income } \\
\text { (Rs/week) }\end{array}$ & $239.9 \pm 136.3$ & $249.2 \pm 192.6$ & $213.9 \pm 145.9$ & $170.0 \pm 93.2$ & 0.354 \\
\hline $\begin{array}{l}\text { Income of index case } \\
\text { (Rs/week) }\end{array}$ & $88.8 \pm 101.2$ & $80.7 \pm 128.2$ & $40.4 \pm 75.7$ & $28.8 \pm 43.1$ & 0.105 \\
\hline $\begin{array}{l}\text { Money spent on food } \\
\text { (Rs/week) }\end{array}$ & $123.3 \pm 56.6$ & $102.6 \pm 55.1$ & $99.9 \pm 70.1$ & $113.3 \pm 46.4$ & 0.199 \\
\hline $\begin{array}{l}\text { Cereal intake of index } \\
\text { case (kcal/day) }\end{array}$ & $2202.9 \pm 752.1$ & $2131.0 \pm 811.2$ & $2105.9 \pm 756.9$ & $1697.1 \pm 762.8$ & 0.160 \\
\hline
\end{tabular}

All mean $\pm \mathrm{SD}$, statistical analysis using one-way ANOVA. 
The extent of disability, total household income and reported food expenditure were all not significantly correlated with the extent of undernutrition in the index case.

\section{Discussion}

There is considerable literature on the principles involved in the successful implementation of community based rehabilitation programmes. ${ }^{16}$ There are few data, however, on the methods of prioritization of disabled individuals for rehabilitation interventions. Historically, early reports of effective community based rehabilitation focused more on the positive changes in individuals who were rehabilitated, rather than the process involved in the choice of these individuals. ${ }^{17}$ Towards the latter part of the 1990s there have been calls for more accurate methods to assess the global needs in relation to rehabilitation, ${ }^{5,9}$ culminating in comprehensive guidelines. ${ }^{8}$

The data of this study demonstrate the simplicity with which nutritional status can be assessed anthropometrically. Fifty-seven percent of the leprosy patients with residual disability had some degree of undernutrition. In approximately $10 \%$ of patients, the extent of undernutrition was severe (grade III). The only significant correlate of undernutrition in the individual with disability was personal income. Reported household income, amount of money spent on food, and estimated cereal intake were not correlated with the BMI of the individual, although the mean value of all these parameters was lower (NS) in leprosy patients with grade III undernutrition as compared to those who were well nourished.

As mentioned earlier, it has been suggested that those with physical disability whose social and economic life are under threat or already dislocated should be seen as the primary targets for SER. ${ }^{8}$ The issue then is to quantify the 'threat' or 'dislocation'. Personal and household income, possessions and assets are all obvious measures and have been advocated in the initial needs assessment of leprosy patients with disability. ${ }^{8}$ Some of these, however, like income and amount of money spent on food, are subject to reporting bias and are difficult to verify in situations where individuals are self employed, where employment may be intermittent, and where food procurement is variable, and dependent on variable financial situations. This may account for the poor correlation between nutritional status and other economic indicators in our study. It is our contention, based on a large body of data, ${ }^{13}$ that in the absence of disease, undernutrition is reflective of a poor economic status and should be included as part of the needs assessment of disabled leprosy patients being evaluated for SER. Furthermore, undernutrition in the index case also reflects an increased household vulnerability as evidenced by the increased burden of undernutrition in these households. ${ }^{3}$ Figure 1 outlines the natural process that links nutritional status to primary measures of economic status like income. While some measures of nutrition are cumbersome and fraught with methodological issues; the estimation of food intake, for instance, ${ }^{18}$ the advantages of nutritional status assessment by anthropometry are that it is objective, and simple to perform, requiring no more than the measurement of height and weight in adults.

The title of this paper poses a question: should nutritional status evaluation be included in the initial needs evaluation of leprosy patients? Based on the data of this study, we believe it should. The data clearly demonstrates that within a group of disabled leprosy patients, simple anthropometry allows the categorization of subjects along a nutritional spectrum. Grade 1 undernutrition in the presence of other lowered economic indicators like income is likely to represent economic 'threat', while grade III undernutrition is more likely to represent 


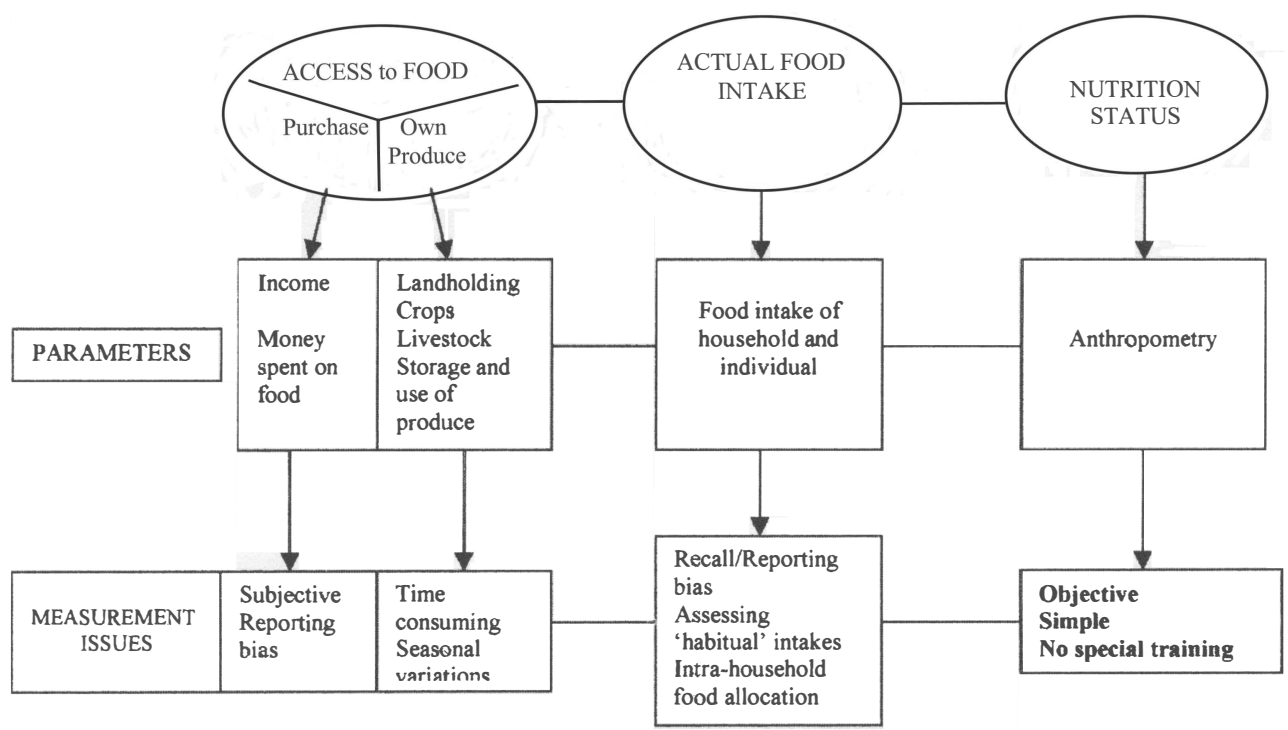

Figure 1. Flow chart indicating potential parameters that can be used to assess nutritional vulnerability as economic indices, and the specific role of anthropometry.

economic 'dislocation'. We accordingly propose that heights and weights of disabled adult leprosy patients, be routinely recorded as a part of the initial assessment of patients prior to SER. The presence and extent of undernutrition can be assessed using the cut-offs in this paper, and delineated earlier. ${ }^{12,13}$

\section{Acknowledgements}

B. D. was supported by a grant from the Deakin University, Australia.

\section{References}

${ }^{1}$ WHO. Leprosy disabilities: magnitude of the problem. Weekly Epidemiol Rec, 1995; 70: 269-275.

2 Kopparty SNM, Kurup AM, Sivaram M. Problems and coping strategies of families having patients with and without deformities. Ind J Lepr, 1995; 67: 133-152.

${ }^{3}$ Diffey B, Vaz M, Soares MJS et al. The effect of leprosy induced deformity on the nutritional status of index cases and their household members in rural South India: a socio-economic perspective. Eur J Clin Nutr, 2000; 54: 643649.

${ }^{4}$ Max E, Shepard DS. Productivity loss due to deformity from leprosy in India. Int J Lepr, 1989; 57: 476-482.

5 Walter CS. International Leprosy Congress, Beijing, 7-12 September 1998. Workshop Reports. Social Aspects and Rehabilitation. Lepr Rev, 1999; 70: 85-94.

${ }^{6}$ Helander E. Global statistics on disability. In: Proceedings of the International Congress 'Disability and Developing Countries: which rehabilitation'. Assciazione Italiana, Amici di R. Follereau, Organizzazione per la Cooperazione Sanitaria Internationale (OCSI), Bologna, 1990, pp 17-21.

7 Smith WCS, Jesudasan K. Elimination of leprosy and prospects for rehabilitation. Lancet, 1993; 341: 89-90.

${ }^{8}$ Nicholls PG. Guidelines for social and economic rehabilitation. Lepr Rev, 2000; 71: 422-465.

9 Workshop Report. Identifying and assessing the magnitude of leprosy patients requiring rehabilitation. Tirupati (A.P.) 3-5 March, 1997. Ind J Lepr, 1997; 69: 438-443.

${ }^{10}$ Bechelli LM, Dominguez VM. Disability index for leprosy patients. Bull WHO, 1971; 44: 709-713. 
Gopalan C, Rama Sastri BV, Balasubramanian SC. Nutritive value of Indian foods. National Institute of Nutrition, Indian Council of Medical Research, Hyderabad, 1996, p 9.

' Ferro-Luzzi A, Sette S, Franklin M, James WPT. A simplified approach to assessing adult chronic energy deficiency. Eur J Clin Nutr, 1992; 46: 173-186.

${ }^{3}$ Shetty PS, James WPT. Body mass index. A measure of chronic energy deficiency in adults. FAO Food and Nutrition Paper 56, FAO, Rome, 1994.

+ WHO. Physical status: the use and interpretation of anthropometry. Report of WHO Expert Committee.

${ }^{5}$ Hamill PVV, Drizd TA, Johnson CL et al. Physical growth: National Centre for Health Statistics percentiles. Am J Clin Nutr, 1979; 32: 607-629.

${ }^{5}$ Helander E. The principles of community-based rehabilitation. In: Proceedings of the International Congress 'Disability and Developing Countries: which rehabilitation'. Assciazione Italiana, Amici di R. Follereau, Organizzazione per la Cooperazione Sanitaria Internationale (OCSI), Bologna, 1990, pp 35-43.

${ }^{7}$ Gershon W, Srinivas GR. Community based rehabilitation: an evaluation study. Lepr Rev, 1992; 63: 51-59.

${ }^{8}$ Nelson M, Bingham SA. Assessment of food consumption and nutrient intake. In: Margetts BM, Nelson M (eds) Design concepts in nutritional epidemiology, 2nd edn. Oxford University Press, Oxford, 1998, pp 123-169. 